Article

\title{
Photocatalytic Membrane Reactor for the Removal of C.I. Disperse Red 73
}

\author{
Valentina Buscio ${ }^{1}$, Stephan Brosillon ${ }^{2}$, Julie Mendret ${ }^{2}$, Martí Crespi ${ }^{1}$ and \\ Carmen Gutiérrez-Bouzán 1,*
}

1 Institut d'Investigació Tèxtil i Cooperació Industrial de Terrassa (INTEXTER), Universitat Politècnica de Catalunya-BarcelonaTech (UPC). C/Colom 15, Terrassa 08222, Spain;

E-Mails: valentina.buscio@intexter.upc.edu (V.B.); crespi@etp.upc.edu (M.C.)

2 Institut Européen des Membranes (IEM), UMR Université Montpellier 2 Place E. Bataillon, Montpellier F-34095, France; E-Mails: Stephan.Brosillon@univ-montp2.fr (S.B.);

Julie.Mendret@univ-montp2.fr (J.M.)

* Author to whom correspondence should be addressed; E-Mail: gutierrez@intexter.upc.edu;

Tel.: +34-93-739-8008; Fax: +34-93-739-8272.

Academic Editor: Harold Freeman

Received: 7 April 2015 / Accepted: 11 June 2015 / Published: 18 June 2015

\begin{abstract}
After the dyeing process, part of the dyes used to color textile materials are not fixed into the substrate and are discharged into wastewater as residual dyes. In this study, a heterogeneous photocatalytic process combined with microfiltration has been investigated for the removal of C.I. Disperse Red 73 from synthetic textile effluents. The titanium dioxide $\left(\mathrm{TiO}_{2}\right)$ Aeroxide P25 was selected as photocatalyst. The photocatalytic treatment achieved between $60 \%$ and $90 \%$ of dye degradation and up to $98 \%$ chemical oxygen demand (COD) removal. The influence of different parameters on photocatalytic degradation was studied: $\mathrm{pH}$, initial photocatalyst loading, and dye concentration. The best conditions for dye degradation were $\mathrm{pH} 4$, an initial dye concentration of $50 \mathrm{mg} \cdot \mathrm{L}^{-1}$, and a $\mathrm{TiO}_{2}$ loading of $2 \mathrm{~g} \cdot \mathrm{L}^{-1}$. The photocatalytic membrane treatment provided a high quality permeate, which can be reused.
\end{abstract}

Keywords: photocatalytic membrane reactor; titanium dioxide; C.I. Disperse Red 73; UV light; polysulfone membrane; microfiltration 


\section{Introduction}

Synthetic dyes are widely used in the textile industry. Approximately 800,000 tonnes of dyes are produced annually worldwide [1]. However, about $15 \%$ of the dyes consumed are lost in the textile effluents [2]. Textile wastewater is characterized by its high chemical oxygen demand (COD), salinity, variable $\mathrm{pH}$ values, and high temperature [3-6]. In addition, the presence of a very low concentration of dyes in wastewater is highly visible [7].

The dyes are classified according to how they are applied in the dyeing process. The most common dyes are reactive, acid, and disperse. Reactive dyes are water-soluble, mainly applied to cotton. Acid dyes are water-soluble and applied from an acidic solution to nylon, wool, silk, and some modified acrylic textiles. Finally, disperse dyes are used for polyesters fibers. They have very low water solubility, so they are applied as a dispersion in the dyeing process [8].

Many processes have been studied to treat textile wastewater in order to remove color. The most used treatments are physical and chemical techniques such as coagulation-flocculation, adsorption, or membrane processes. Nonetheless, these treatments do not destroy the dye and a post-treatment, such as incineration, is required [9].

In recent years, the interest for advanced oxidation processes (AOPs) has increased, especially heterogeneous photocatalytic processes. Titanium dioxide $\left(\mathrm{TiO}_{2}\right)$ is the most used photocatalyst due to its good photocatalytic activity, nontoxicity, chemical inertness, and low cost [10].

The heterogeneous photocatalytic process starts when a semiconductor absorbs photons whose energy is equal to or greater than its band gap (e.g., $=3.2 \mathrm{eV}$ for $\mathrm{TiO}_{2}$ ). This adsorption enables the promotion of an electron $\left(\mathrm{e}^{-}\right)$from the valence band $(\mathrm{vb})$ of the semiconductor to the conduction band $(\mathrm{cb})$, generating holes $\left(\mathrm{h}^{+}\right)$in the valence band [11]. The recombination of the electron and the hole must be prevented.

The electron can reduce the organic species or react with the $\mathrm{O}_{2}$, which is either adsorbed on the semiconductor surface or dissolved in water, reducing it to a superoxide radical anion $\left(\mathrm{O}_{2}^{-\bullet}\right)$. The hole can oxidize the organic molecule or react with $\mathrm{OH}^{-}$or $\mathrm{H}_{2} \mathrm{O}$, oxidizing them into $\mathrm{OH}^{\bullet}$ radicals [12].

The highly oxidant species generated during the photocatalytic process are responsible for the photodegradation of organic substrates such as dyes. The process can be expressed according to Equations (1)-(8) [11,13]:

$$
\begin{gathered}
\mathrm{TiO}_{2}+\mathrm{hv}(\mathrm{UV}) \rightarrow \mathrm{TiO}_{2}\left(\mathrm{e}_{\mathrm{CB}}{ }^{-}+\mathrm{h}_{\mathrm{VB}}{ }^{+}\right) \\
\mathrm{TiO}_{2}\left(\mathrm{~h}_{\mathrm{VB}}{ }^{+}\right)+\mathrm{H}_{2} \mathrm{O} \rightarrow \mathrm{TiO}_{2}+\mathrm{H}^{+}+\mathrm{OH}^{\bullet} \\
\mathrm{TiO}_{2}\left(\mathrm{~h}_{\mathrm{VB}}{ }^{+}\right)+\mathrm{OH}^{-} \rightarrow \mathrm{TiO}_{2}+\mathrm{OH}^{\bullet} \\
\mathrm{TiO}_{2}\left(\mathrm{e}_{\mathrm{VB}}^{-}\right)+\mathrm{O}_{2} \rightarrow \mathrm{TiO}_{2}+\mathrm{O}_{2}^{-} \\
\mathrm{O}_{2}^{-}{ }^{-}+\mathrm{H}^{+} \rightarrow \mathrm{HO}_{2}{ }^{-} \\
\text {Dye }+\mathrm{OH}^{\cdot} \rightarrow \text { degradation products } \\
\text { Dye }+\mathrm{h}_{\mathrm{VB}}^{+} \rightarrow \text { oxidation products } \\
\text { Dye }+\mathrm{e}_{\mathrm{VB}}{ }^{-} \rightarrow \text { redeuction products }
\end{gathered}
$$


The oxidation species responsible for organic substrate degradation depends on experimental conditions ( $\mathrm{pH}$, pollutant, concentration, etc.). The dominant oxidative species can be identified adding different species quenchers [14].

The main limitation of the photocatalytic process is the recovery of the photocatalyst from the solution. This problem can be solved by doing a coupling of photocatalysis with membrane processes [15]. In addition, this coupling enables the confinement of the photocatalyst in the reaction environment, the control of the residence time of the molecule in the reactor by means of the transmembrane flux, and the achievement of a continuous process with simultaneous photocatalyst and product separation from the reaction environment. Heterogeneous photocatalytic oxidation may be combined with different membrane processes, such as microfiltration (MF) [16-19], ultrafiltration (UF) [20-22], nanofiltration (NF) $[23,24]$, and direct contact membrane distillation (DCMD, MD) [10,25,26]. Photocatalytic membrane reactors (PMRs) described in the literature can be divided into two groups: (I) reactors with photocatalysts suspended in a feed solution and (II) reactors with photocatalysts supported on the membrane [27]. A comparison between PMRs with a photocatalyst in suspension and with a photocatalyst supported on a membrane on the purification of water contaminated with dyes was reported by Grzechulska et al. [28]. The authors studied the degradation of three dyes: C.I. Acid Red 18, C.I. Acid Yellow 36, and C.I. Direct Green 99. Results showed that the time of discoloration was shorter in the suspended system than in case of the supported photocatalyst.

Several studies with photocatalysts in suspension have been reported to treat different solutions containing dyes. In general, color removal of reactive dyes [10,29] and acid dyes [16,30] has been widely investigated, but fewer studies have been carried out on disperse dyes despite the fact that they are used for dyeing polyester fibers, which are the most consumed fibers in the world. Due to the high worldwide consumption of polyester, the interest for the disperse dyes and their associated environmental problems has increased in recent years [31]. It is important to highlight that after the dyeing process, the dye is not totally adsorbed by polyester and it is discharged into wastewater. A proper removal of disperse dye in the effluent would allow the water to be reused, which is an important advantage from the economic and environmental points of view.

Taking into account these considerations, this paper investigates the potential use of a photocatalytic membrane reactor for the degradation of C.I. Disperse Red 73 (DR73) using $\mathrm{TiO}_{2}$ in suspension as a photocatyst. In order to optimize the process, the effect of several parameters such as $\mathrm{pH}$, initial dye concentration, and $\mathrm{TiO}_{2}$ loading on photodegradation efficiency was tested. As far as we know, no studies based on the degradation of disperse dyes by means of photocatalytic membrane reactor have been carried out.

\section{Experimental Section}

\subsection{Reagents}

The photocatalyst used in this study was commercial $\mathrm{TiO}_{2}$ powder (Sigma-Aldrich). The average diameter of $\mathrm{TiO}_{2}$ particles was $21 \mathrm{~nm}$ and BET was $50 \pm 15 \mathrm{~m}^{2} \cdot \mathrm{g}^{-1}$.

C.I. Disperse Red 73 was supplied by Archroma (Figure 1). Its molecular weight is $348 \mathrm{~g} \cdot \mathrm{moL}^{-1}$. 


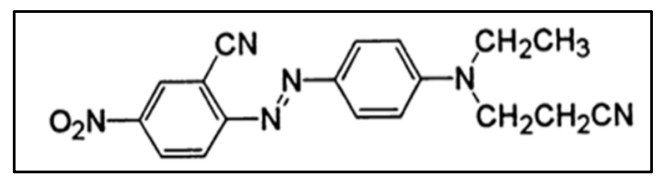

Figure 1. Chemical structure of Disperse Red 73 (DR73).

To determine the dye concentration, $N, N$-dimethylformamide (purity 99\%, Merck) and deionised water were employed as solvents.

The $\mathrm{pH}$ of synthetic effluents containing DR73 was adjusted with $1 \mathrm{M}$ solutions of $\mathrm{NaOH}$ or $\mathrm{HCl}$.

\subsection{Photocatalytic Membrane Experiments}

The photocatalytic membrane reactor was equipped with a photocatalytic reactor $(2.2 \mathrm{~L})$ and an outside membrane module (0.3 L) (Figure 2).
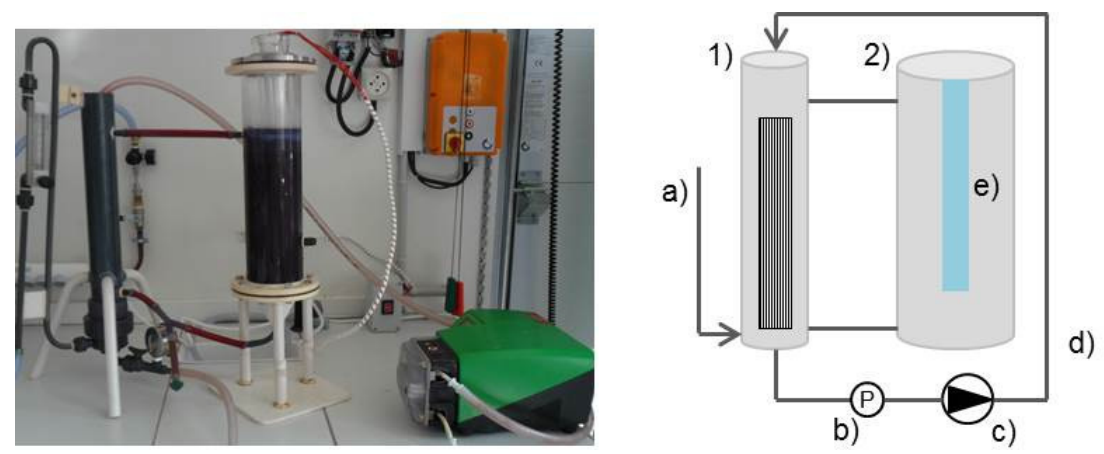

Figure 2. Photocatalytic membrane reactor: (1) membrane reactor; (2) photocatalytic reactor; (a) air inlet; (b) pressure measurement; (c) peristaltic pump; (d) permeate; and (e) UV lamp.

A hollow fiber membrane module manufactured by Polymem Company (Toulouse, France) was used. Its main specifications and operation characteristics are shown in Table 1.

Table 1. Membrane characteristics.

\begin{tabular}{cc}
\hline Material & Polysulfone \\
\hline Nominal pore size $(\mu \mathrm{m})$ & 0.2 \\
External diameter $(\mathrm{mm})$ & 1.4 \\
Fiber length $(\mathrm{cm})$ & 32 \\
Surface area $\left(\mathrm{m}^{2}\right)$ & 0.3 \\
Hydraulic resistance $\left(\mathrm{m}^{-1}\right)$ & $4 \cdot 1011$ \\
Pure water permeability at $20^{\circ} \mathrm{C}\left(\mathrm{L} \cdot \mathrm{h}^{-1} \cdot \mathrm{m}^{-2} \cdot\right.$ bar $)$ & 227 \\
\hline
\end{tabular}

Air was injected at a flow rate of $200 \mathrm{~L} \cdot \mathrm{h}^{-1}$ through a diffuser placed at the bottom of the membrane module. This injection of air enables an air lift and then the liquid goes from the membrane module to the photoreactor. This circulation allowed the homogenization of the solution.

A peristaltic pump (Watson-Marlow) was used to fix the permeate flux at $20 \mathrm{~L} \cdot \mathrm{h}^{-1} \cdot \mathrm{m}^{-2}$ and to recirculate the permeate to the membrane module. 
The light source was a $24 \mathrm{~W}$ UV lamp PL-L 24 W/10/4P (Philips, Amsterdam, The Netherlands), with a wavelength of $365 \mathrm{~nm}$, located in a quartz vessel in the centre of the photocatalytic reactor.

To simulate the effluents discharged after the dyeing process, solutions of DR73 were prepared in deionised water. Before photodegradation, the dye- $\mathrm{TiO}_{2}$ mixture was kept for $30 \mathrm{~min}$ in the dark in order to allow adsorption of the dye molecules on the $\mathrm{TiO}_{2}$ surface. The effects of different parameters on the process were tested. Photocatalytic experiments were conducted at different $\mathrm{pH}$ levels $(4,6$, and 10), different amounts of $\mathrm{TiO}_{2}$ (between 0.5 and $\left.2 \mathrm{~g} \cdot \mathrm{L}^{-1}\right)$, and different initial dye concentrations $(50,75$, and $\left.100 \mathrm{mg} \cdot \mathrm{L}^{-1}\right)$.

\subsection{Analytical Methods and Measurements}

The membrane fouling was evaluated by recording the $\Delta \mathrm{P}$ and measuring the normalized water permeability with Equation (9).

$$
\operatorname{Lp}\left(20^{\circ} \mathrm{C}\right)=\mathrm{J} / \Delta \mathrm{P} \cdot \mu\left(20^{\circ} \mathrm{C}\right) / \mu \mathrm{T}
$$

where $\mathrm{J}$ is the permeate flux $\left(\mathrm{m}^{3} \cdot \mathrm{m}^{-2} \cdot \mathrm{s}^{-1}\right), \Delta \mathrm{P}$ is the transmembrane pressure $(\mathrm{Pa}), \mu\left(20{ }^{\circ} \mathrm{C}\right)$ is the viscosity of the fluid at $20{ }^{\circ} \mathrm{C}(\mathrm{Pa} \cdot \mathrm{s})$, and $\mu_{\mathrm{T}}$ is the viscosity of the fluid at working temperature $(\mathrm{Pa} \cdot \mathrm{s})$.

Samples were taken from the photocatalytic reactor and then centrifuged with a Sigma 3-16 k centrifuge in order to separate the $\mathrm{TiO}_{2}$ particles from the solution.

Dye removal $\left(\% \mathrm{R}_{\text {dye }}\right)$ was calculated from concentrations of dye in the feed and the photocatalytic reactor using Equation (10):

$$
\% \mathrm{R}_{\text {dye }}=\left(\left(\mathrm{C}_{\mathrm{f}}-\mathrm{C}_{\mathrm{t}}\right) / \mathrm{C}_{\mathrm{f}}\right) \cdot 100
$$

where $C_{f}$ and $C_{t}$ are the concentrations of dye in the feed and the photocatalytic reactor at time $t$, respectively. The dye was dissolved in a solution of water $/ N, N$-dimethylformamide $(1 / 1, v / v)$, and its concentration was determined with a UV-Vis spectrophotometer UV-2401 (Shimadzu Corporation, Kyoto, Japan) at the maximum wavelength of the visible spectrum $\left(\lambda_{\max }=528 \mathrm{~nm}\right)$.

COD was determined according to the method 5220 D recommended by American Public Health Association [32]. The COD reduction (\% $\mathrm{R} \mathrm{COD}$ ) was calculated using Equation (11):

$$
\% \mathrm{R}_{\mathrm{COD}}=\left(\left(\mathrm{COD}_{\mathrm{f}}-\mathrm{COD}_{\mathrm{p}}\right) / \mathrm{COD}_{\mathrm{f}}\right) \cdot 100
$$

where $\mathrm{COD}_{\mathrm{f}}$ and $\mathrm{COD}_{\mathrm{p}}$ are the COD values in the feed and permeate, respectively.

The $\mathrm{pH}$ was determined according to the method $4500 \mathrm{H}^{+} \mathrm{B}$ [32] using a $\mathrm{pH}$ meter Ion 510 (Eutech Instruments, Landsmeer, The Netherlands).

\section{Results and Discussion}

\subsection{Previous Studies}

Some dyes can be degraded under UV irradiation without a photocatalyst. Before studying the photocatalytic degradation of DR73, the stability of the dye under UV light was tested (Figure 3). 


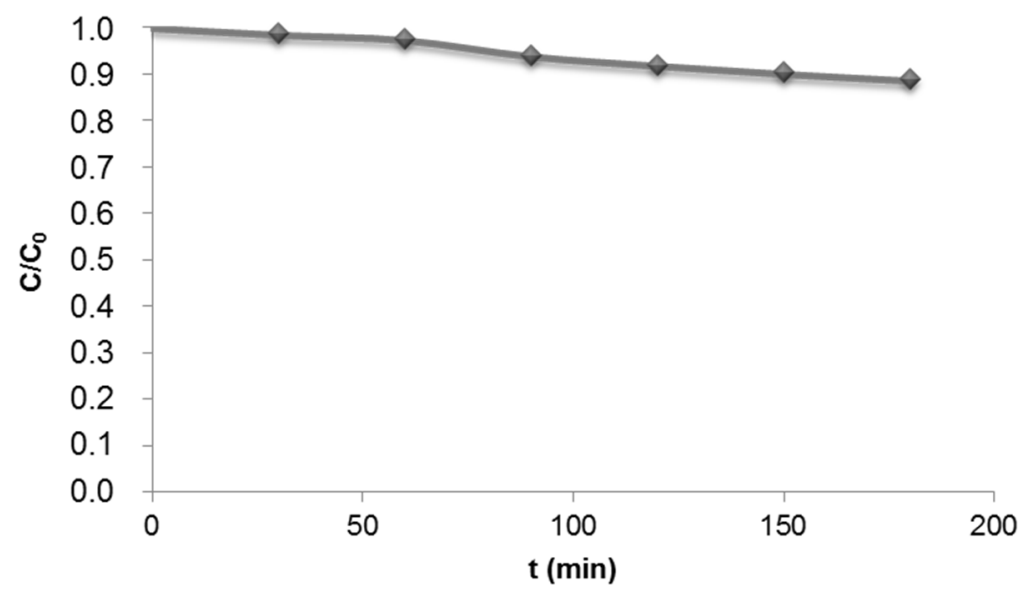

Figure 3. DR73 degradation after $180 \mathrm{~min}$ of $U V$ irradiation $(\lambda=365 \mathrm{~nm})$.

No significant dye degradation was observed after $180 \mathrm{~min}$ of UV irradiation. It is important to highlight that certain disperse dyes are generally characterized by their high light fastness [33]. In the case of DR73 dye, its light fastness is 6 (value 1 indicates very low fastness and 8 corresponds to high fastness).

\subsection{Photocatalytic Degradation of DR73}

\subsubsection{Effect of Initial $\mathrm{pH}$}

The $\mathrm{pH}$ affects both the surface properties of the photocatalyst and the physical properties of dye solution, such as dye aggregation or dispersion. The effect of the $\mathrm{pH}$ was studied using a solution of $75 \mathrm{mg} \cdot \mathrm{L}^{-1}$ of DR73 and a $\mathrm{TiO}_{2}$ dosage of $1 \mathrm{~g} \cdot \mathrm{L}^{-1}$.

Comparing experiments carried out at different $\mathrm{pH}$ values $(4,6$, and 10$)$, it can be observed that, after 180 min of UV irradiation, the highest dye degradation (90\%) was achieved at $\mathrm{pH} 4$, whereas that at $\mathrm{pH}$ 10 , only $61 \%$ of dye degradation was obtained (Figure 4). The point of zero charge (pzc) of the $\mathrm{TiO}_{2}$ Aeroxide $\mathrm{P} 25$ is reported to be at $\mathrm{pH}$ 6.5. Thus, the $\mathrm{TiO}_{2}$ surface is positively charged in an acidic medium $(\mathrm{pH}<6.5)$ and it is negatively charged in an alkaline medium $(\mathrm{pH}>6.5)$, as is shown in Equations (12) and (13) [34].

$$
\begin{gathered}
\text { When pH }<\text { pzc: } \mathrm{TiOH}+\mathrm{H}^{+} \leftrightarrow \mathrm{TiOH}_{2}^{+} \\
\text {When pH }>\text { pzc: } \mathrm{TiOH}+\mathrm{OH}^{-} \leftrightarrow \mathrm{TiO}^{-}+\mathrm{H}_{2} \mathrm{O}
\end{gathered}
$$

At $\mathrm{pH}$ lower than 6.5 , the $\mathrm{TiO}_{2}$ is positively charged and attracts the negatively charged species from the solution, facilitating their photodegradation. The dye studied in this project is negatively charged in water solution. 


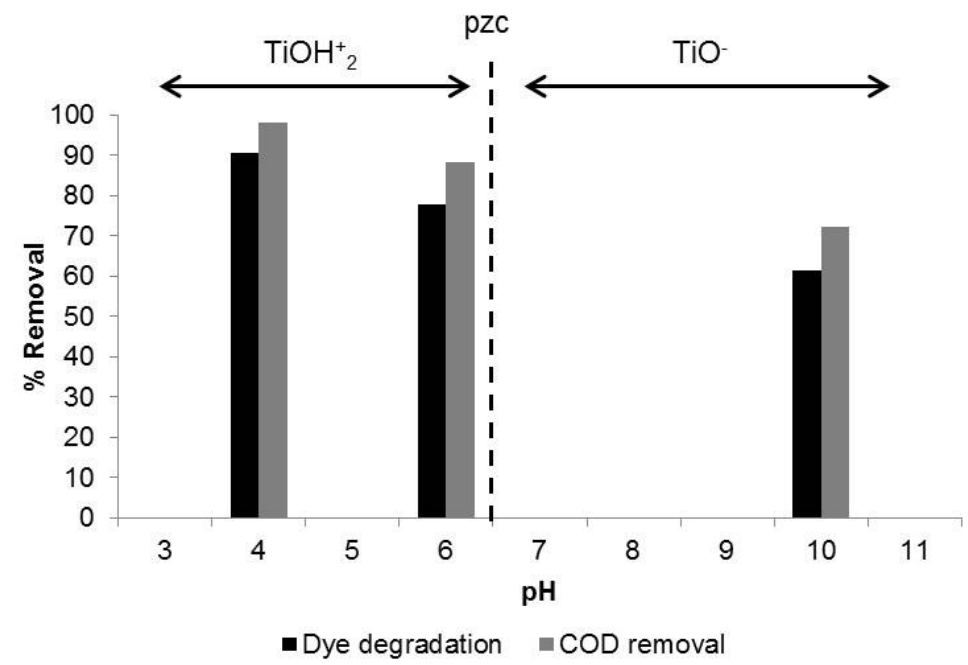

Figure 4. Influence of $\mathrm{pH}$ solution on the degradation of DR73.

Although the mechanism of degradation was not the aim of this work, several studies [11,14] have reported that, in acidic medium, holes are the major oxidation species, whereas at high $\mathrm{pH}$, hydroxyl radicals are considered the predominant species.

As expected, the COD removal followed the same trend as the degradation of dye. About $98 \%$ of COD removal was obtained at $\mathrm{pH} 4,88 \%$ at $\mathrm{pH} 7$, and $72 \%$ at $\mathrm{pH} 10$.

Several authors $[35,36]$ reported that in very acidic medium, the strong adsorption of the dye particles on the $\mathrm{TiO}_{2}$ surface could reduce the active centres on the photocatalyst surface. On the other hand, in alkaline medium, the dye particles are hardly adsorbed on the catalyst surface. In addition, the dyeing process with disperse dyes is carried out at a $\mathrm{pH}$ between 5.5 and 6.5 [33]. A change of $\mathrm{pH}$ implies an increase in the conductivity of the effluents, which is one of the main problems of textile wastewater. For these reasons, pH 6 was selected for the subsequent studies.

\subsubsection{Effect of Photocatalyst Loading}

To determine the influence of the photocatalyst loading in the process, a solution of $75 \mathrm{mg} \cdot \mathrm{L}^{-1}$ at $\mathrm{pH} 6$ was used.

As can be observed in Figure 5, the COD removal ranged from $70 \%$ to $90 \%$ for the tested concentration of $\mathrm{TiO}_{2}$. The photocatalyst loading of $0.5 \mathrm{~g} \cdot \mathrm{L}^{-1}$ and $1 \mathrm{~g} \cdot \mathrm{L}^{-1}$ provided similar dye degradation (about 75\%). However, when $2 \mathrm{~g} \cdot \mathrm{L}^{-1}$ of $\mathrm{TiO}_{2}$ was used, a remarkable increase of the dye degradation (90\%) was observed. 


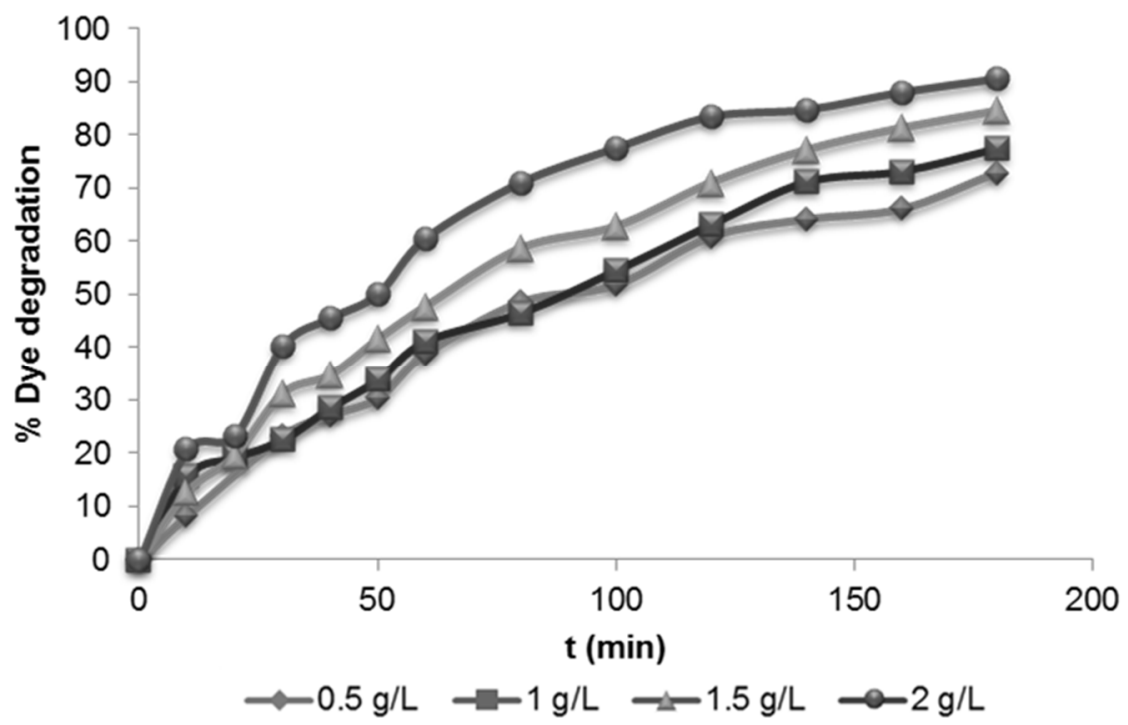

Figure 5. Evolution of the dye degradation for different $\mathrm{TiO}_{2}$ loading (initial dye concentration $=75 \mathrm{mg} \cdot \mathrm{L}^{-1}$ ).

Nonetheless, it is important to highlight that an excess of photocatalyst can produce a light screening, which causes a reduction in the surface area exposed to irradiation and thus could reduce the photocatalytic efficiency of the process [37].

Taking into account these considerations and to prevent membrane fouling, $1 \mathrm{~g} \cdot \mathrm{L}^{-1}$ of $\mathrm{TiO}_{2}$ was selected for subsequent experiments.

\subsubsection{Effect of Initial Dye Concentration}

The effect of the initial dye concentration was tested at a constant $\mathrm{TiO}_{2}$ dosage $\left(1 \mathrm{~g} \cdot \mathrm{L}^{-1}\right)$ and $\mathrm{pH}$, with dye concentrations ranging from 50 to $100 \mathrm{mg} \cdot \mathrm{L}^{-1}$. As can be observed in Figure 6 , the dye degradation decreased (from $87 \%$ to $62 \%$ ) when the dye concentration increased.

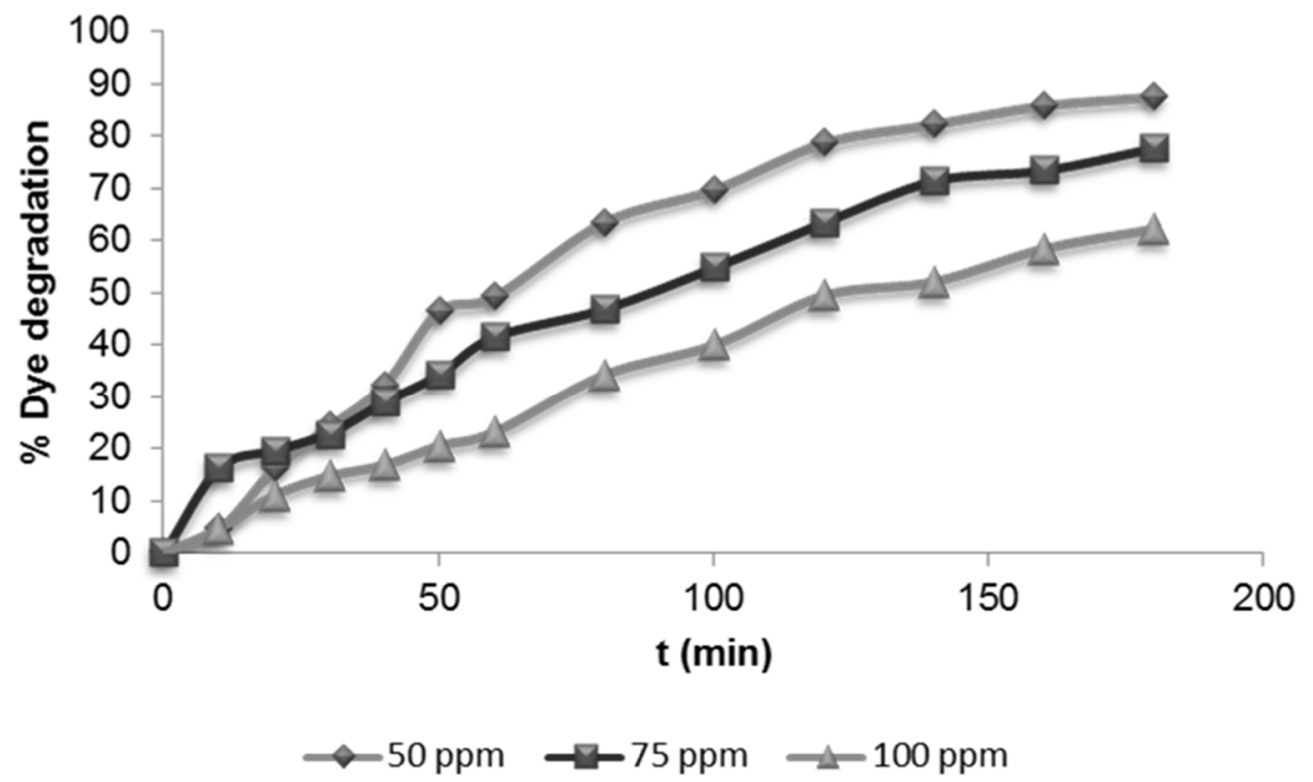

Figure 6. Influence of the initial dye concentration on dye degradation $\left(1 \mathrm{~g} \cdot \mathrm{L}^{-1} \mathrm{TiO}_{2}\right)$. 
The higher the dye concentration, the higher the adsorption of the dye on the photocatalyst surface, which produced a decrease of $\mathrm{OH}^{-}$adsorption and, consequently, diminished the formation of $\mathrm{OH}^{*}$ radical, the principal oxidant in the photocatalysis process [38]. In addition, at a high dye concentration, the UV light might be absorbed by dye instead of the $\mathrm{TiO}_{2}$ particles. Similar results have been reported for the photocatalytic degradation of reactive [29,39] and direct dyes [40,41] and pharmaceutical compounds $[42,43]$. Liang et al. [42] observed that the photodegradation reached a saturation limit at high reactant concentration.

Regarding the COD removal (Figure 7), all experiments showed COD decrease higher than $80 \%$.

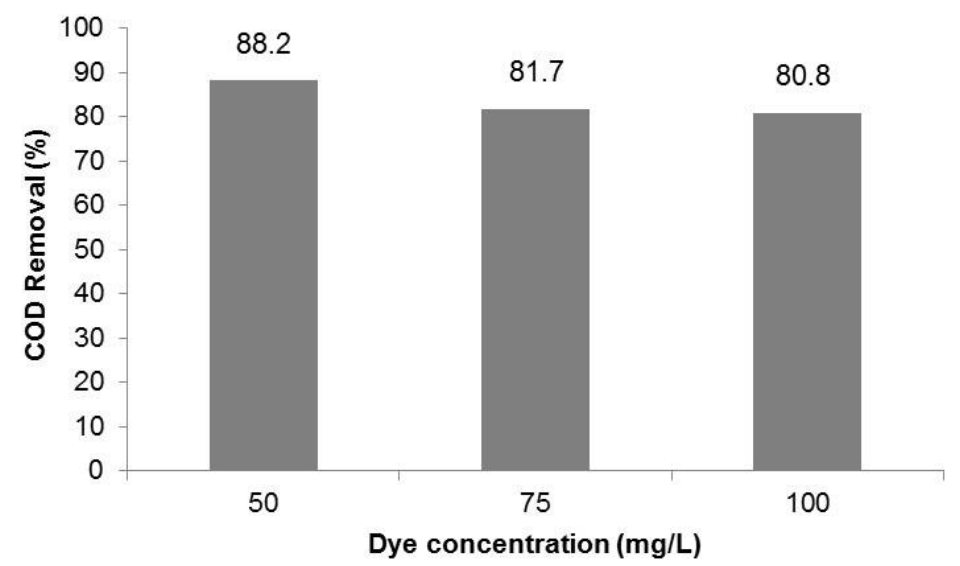

Figure 7. Influence of the dye concentration on COD removal $\left(1 \mathrm{~g} \cdot \mathrm{L}^{-1} \mathrm{TiO}_{2}\right)$.

The effect of the initial concentration of dye on the photocatalytic process can be described by a pseudo-first-order kinetic model with respect to the dye concentration. In general, photocatalytic degradation has a kinetic model according to Langmuir-Hinshelwood [15,16]:

$$
\mathrm{R}=\mathrm{dC} / \mathrm{dt}=-\mathrm{kC}
$$

Integrating Equation (14) with respect to time t, it can be simplified to the pseudo-first-order kinetic model Equation (15):

$$
\ln \left(\mathrm{C}_{0} / \mathrm{C}_{\mathrm{t}}\right)=\mathrm{kapp} \cdot \mathrm{t}
$$

where, $\mathrm{dC} / \mathrm{dt}$ is the rate of dye degradation $\left(\mathrm{mg} \cdot \mathrm{L}^{-1} \cdot \mathrm{min}^{-1}\right), \mathrm{C}_{0}$ and $\mathrm{C}_{\mathrm{t}}$ are initial concentration and concentration at time $\mathrm{t}$ of the dye $\left(\mathrm{mg} \cdot \mathrm{L}^{-1}\right)$, respectively, and kapp is the degradation kinetic rate $\left(\mathrm{min}^{-1}\right)$ [44]. The kapp was calculated from the slope of logarithmic concentration values versus time of treatment (Figure 8). 


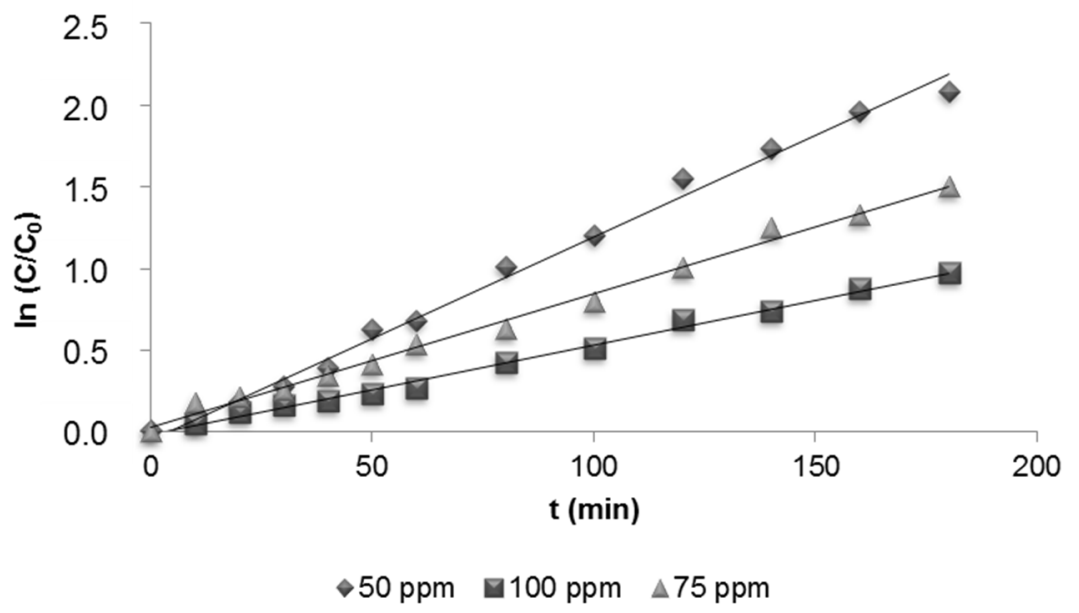

Figure 8. Relationship between $\ln \left(\mathrm{C} / \mathrm{C}_{0}\right)$ and treatment time $\left(\mathrm{t}=180 \mathrm{~min}\right.$ and $\left.1 \mathrm{~g} \cdot \mathrm{L}^{-1} \mathrm{TiO}_{2}\right)$.

The results indicated that the degradation of DR73 fitted first-order kinetics and it followed the Langmuir-Hinshelwood model (Table 2). The value of kapp decreased with the increasing of the dye concentration.

Table 2. The pseudo-first-order degradation rate constants of DR73 at different initial dye concentrations and $1 \mathrm{~g} \cdot \mathrm{L}^{-1} \mathrm{TiO}_{2}$.

\begin{tabular}{ccc}
\hline Dye Concentration $\left(\mathbf{m g} \cdot \mathbf{L}^{-\mathbf{1}}\right)$ & $\mathbf{K}_{\text {app }}\left(\mathbf{m i n}^{-\mathbf{1}}\right)$ & $\mathbf{r}^{\mathbf{2}}$ \\
\hline 50 & 0.0124 & 0,9937 \\
75 & 0.0082 & 0,9934 \\
100 & 0.0055 & 0,9943 \\
\hline
\end{tabular}

\subsection{Photocatalytic Membrane Treatment}

\subsubsection{Permeate Quality}

A synthetic effluent containing $75 \mathrm{mg} \cdot \mathrm{L}^{-1} \mathrm{DR} 73$ and $119 \mathrm{mgO} \cdot \mathrm{L}^{-1} \mathrm{COD}$ was treated by means of a photocatalytic membrane reactor. The characterization of the permeate after $180 \mathrm{~min}$ of treatment showed dye concentrations lower than $0.5 \mathrm{mg} \cdot \mathrm{L}^{-1}$ and COD values of about $10 \mathrm{mg} \cdot \mathrm{L}^{-1}$. A full mineralization of the dye would probably be achieved with longer treatment, but with high associated cost. However, our previous studies [45] have shown that permeates with higher residual organic matter content are able to be successfully reused in new dyeing processes with disperse dyes. Due to the high water consumption in the textile industry, water reuse is an important challenge with advantages from both economical and environmental points of view.

\subsubsection{Effect of Photocatalytic Treatment on Membrane Fouling}

The maintenance of the membrane is also an important point to take into account for the industrial application of the technology.

Generally, a significant fouling is observed when the photocatalysis process is combined with pressure-driven membrane processes, such as MF and UF [46,47], which results in either a flux decrease 
or a $\Delta \mathrm{P}$ increase. To establish the factor affecting the membrane fouling, the $\Delta \mathrm{P}$ was recorded with three effluents: pure water, water containing $1 \mathrm{~g} \cdot \mathrm{L}^{-1}$ of $\mathrm{TiO}_{2}$, and a dye solution of $75 \mathrm{mg} \cdot \mathrm{L}^{-1}$.

It was observed that when the solution with a photocatalyst was treated, the pressure increased with respect to the $\Delta \mathrm{P}$ obtained with pure water, although it remained constant during the whole experiment. Thus, the presence of the photocatalyst produced an initial fouling on the membrane that did not increase along the experiment. According to Damodar et al. [29], this result could indicate that the $\mathrm{TiO}_{2}$ particles formed a very porous cake layer on the membrane surface. Finally, when the dye solution was treated, an increase of pressure was observed during the experiment indicating the formation of a dye deposit.

During the photocatalytic treatment, the $\mathrm{pH}$ was found to be the most influent parameter on the membrane fouling. At $\mathrm{pH} 10$, an important increase of the $\Delta \mathrm{P}$ was observed, whereas at $\mathrm{pH} 4$, the fouling decreased. The high $\mathrm{pH}$ could influence the stability of the dye dispersion, producing an agglomeration of the dye particles whose size has an influence on fouling.

The efficiency of the cleaning process was determined from the normalized water permeability (NWP) after hydraulic cleaning was carried out at the end of each experiment.

According to results shown in Figure 9, it can be stated that after the treatment of the dye solution, the water permeability of the membrane decreased about $10 \%$. The dye particles were adsorbed on the membrane surface and they only could be completely removed after a chemical washing.

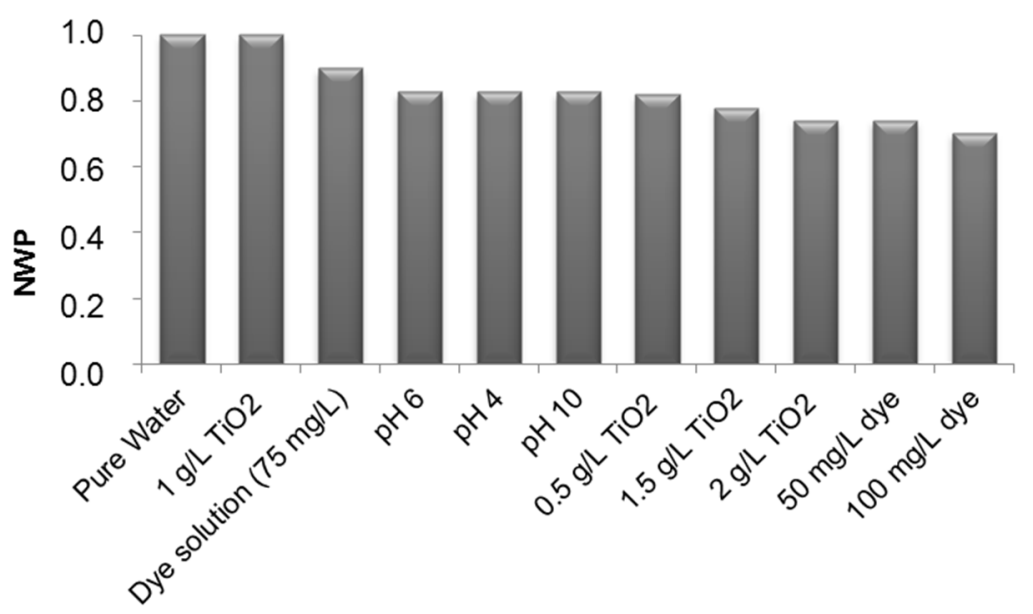

Figure 9. Evolution of normalized water permeability (NWP) for different experimental conditions.

Despite the increase of $\Delta \mathrm{P}$ observed in the experiment carried out at $\mathrm{pH} 10$, the water permeability remained constant at all of the studied $\mathrm{pH}$. This phenomenon indicated that the fouling observed in the alkaline medium was only a physical process.

At the end of all experiments, the membrane water permeability was reduced about $30 \%$.

\section{Conclusions}

For C.I. Disperse Red 73 dye, the photocatalytic treatment provided degradation in the range of $60 \%$ to $90 \%$ and COD removal from $70 \%$ to $98 \%$.

The effect of $\mathrm{pH}$ in the photocatalytic degradation of DR73 was tested and shows that the highest dye degradation was achieved at $\mathrm{pH} 4$ whereas the lowest was at $\mathrm{pH} 10$, which is in accordance with photocatalyst charge. The experiments carried out at different photocatalyst loading indicated that dye 
degradation increased when the photocatalyst concentration increased. From 50 to $100 \mathrm{mg} \cdot \mathrm{L}^{-1}$, the best results were obtained when the initial dye concentration was $50 \mathrm{mg} \cdot \mathrm{L}^{-1}$. As expected, the photocatalytic dye degradation followed the Langmuir-Hinshelwood model.

Finally, the photocatalytic membrane treatment provided an uncolored permeate (dye concentration lower than $0.5 \mathrm{mg} \cdot \mathrm{L}^{-1}$ ) with a low concentration of residual organic matter, which could be reused in new dyeing processes. This study thus demonstrates the feasibility of the coupling of photocatalysis and filtration for the treatment of azo dye wastewater.

\section{Acknowledgments}

Financial support by the Spanish Ministry of Economy and Competitiveness (CTM2012-31461). Valentina Buscio is granted by UPC and AGAUR (CTP2012-00023).

\section{Author Contributions}

Valentina Buscio carried out the experimental work and analysis of results. All the authors planned the experiment and participated in the writing of the manuscript.

\section{Conflicts of Interest}

The authors declare no conflict of interest.

\section{References}

1. Riera-Torres, M.; Gutiérrez, M.-C. Colour removal of three reactive dyes by UV light exposure after electrochemical treatment. Chem. Eng. J. 2010, 156, 114-120.

2. Sapkal, R.T.; Shinde, S.S.; Mahadik, M.A.; Mohite, V.S.; Waghmode, T.R.; Govindwar, S.P.; Rajpure, K.Y.; Bhosale, C.H. Photoelectrocatalytic decolorization and degradation of textile effluent using ZnO thin films. J. Photochem. Photobiol. B 2012, 114, 102-127.

3. Fersi, C.; Gzara, L.; Dhahbi, M. Treatment of textile effluents by membrane technologies. Desalination 2005, 185, 399-409.

4. Riera-Torres, M.; Gutiérrez-Bouzán, C.; Crespi, M. Combination of coagulation-flocculation and nanofiltration techniques for dye removal and water reuse in textile effluents. Desalination 2010, 252, 53-59.

5. Nigmet, U.Z.A.L.; Levent Yilmaz, U.Y. Nanofiltration and Reverse Osmosis for Reuse of Indigo Dye Rinsing Waters. Sep. Sci. Technol. 2010, 45, 331-338.

6. Körbahti, B.K.; Tanyolaç, A. Continuous electrochemical treatment of simulated industrial textile wastewater from industrial components in a tubular reactor. J. Hazard. Mater. 2009, 170, 771-778.

7. Aouni, A.; Fersi, C.; Cuartas-Uribe, B.; Bes-Pía, A.; Alcaina-Miranda, M.I.; Dhahbi, M. Reactive dyes rejection and textile effluent treatment study using ultrafiltration and nanofiltration processes. Desalination 2012, 297, 87-96.

8. Phalakornkule, C.; Polgumhang, S.; Tongdaung, W.; Karakat, B.; Nuyut, T. Electrocoagulation of blue reactive, red disperse and mixed dyes, and application in treating textile effluent. J. Environ. Manag. 2010, 91, 918-926. 
9. Schrank, S.G.; dos Santos, J.N.R.; Souza, D.S.; Souza, E.E.S. Decolourisation effects of Vat Green 01 textile dye and textile wastewater using H2O2/UV process. J. Photochem. Photobiol. A Chem. 2007, 186, 125-129.

10. Qu, D.; Qiang, Z.; Xiao, S.; Liu, Q.; Lei, Y.; Zhou, T. Degradation of Reactive Black 5 in a submerged photocatalytic membrane distillation reactor with microwave electrodeless lamps as light source. Sep. Purif. Technol. 2014, 122, 54-59.

11. Akpan, U.G.; Hameed, B.H. Parameters affecting the photocatalytic degradation of dyes using TiO2-based photocatalysts: A review. J. Hazard. Mater. 2009, 170, 520-529.

12. Zhang, J.; Fu, D.; Gao, H.; Deng, L. Mechanism of enhanced photocatalysis of $\mathrm{TiO} 2$ by $\mathrm{Fe} 3+$ in suspensions. Appl. Surf. Sci. 2011, 258, 1294-1299.

13. Garza-Campos, B.R.; Guzmán-Mar, J.L.; Reyes, L.H.; Hernández-Ramírez, A.; Ruiz-Ruiz, E.J.; Brillas, E. Coupling of solar photoelectro-Fenton with a BDD anode and solar heterogeneous photocatalysis for the mineralization of the herbicide atrazine. Chemosphere 2014, 97, 26-33.

14. Hu, A.; Liang, R.; Zhang, X.; Kurdi, S.; Luong, D.; Huang, H.; Penga, P.; Marzbanrada, E.; Zhou, Y.; Oakesb, K.D.; et al. Enhanced Photocatalytic Degradation of dyes by TiO2 Nanobelts with Hierarchical Structures. J. Photochem. Photobiol. A Chem. 2013, 256, 7-15.

15. Mozia, S. Photocatalytic membrane reactors (PMRs) in water and wastewater treatment. A review. Sep. Purif. Technol. 2010, 73, 71-91.

16. Kertèsz, S.; Cakl, J.; Jiránková, H. Submerged hollow fiber microfiltration as a part of hybrid photocatalytic process for dye wastewater treatment. Desalination 2014, 343, 106-112.

17. Choo, K.H.; Chang, D.I.; Park, K.W.; Kim, M.H. Use of an integrated photocatalysis/hollow fiber microfiltration system for the removal of trichloroethylene in water. J. Hazard. Mater. 2008, 152, 183-190.

18. Yao, P.; Choo, K.-H.; Kim, M.-H. A hybridized photocatalysis-microfiltration system with iron oxide-coated membranes for the removal of natural organic matter in water treatment: Effects of iron oxide layers and colloids. Water Res. 2009, 43, 4238-4248.

19. Horng, R.Y.; Huang, C.; Chang, M.-C.; Shao, H.; Shiau, B.-L.; Hu, Y.-J. Application of TiO2 photocatalytic oxidation and non-woven membrane filtration hybrid system for degradation of 4-chlorophenol. Desalination 2009, 245, 169-182.

20. Reguero, V.; López-Fernández, R.; Fermoso, J.; Prieto, O.; Pocostales, P.; González, R.; Irusta, R.; Villaverde, S. Comparison of conventional technologies and a Submerged Membrane Photocatalytic Reactor (SMPR) for removing trihalomethanes (THM) precursors in drinking water treatment plants. Desalination 2013, 330, 28-34.

21. Jiang, H.; Zhang, G.; Huang, T.; Chen, J.; Wang, Q.; Meng, Q. Photocatalytic membrane reactor for degradation of acid red B wastewater. Chem. Eng. J. 2010, 156, 571-577.

22. Patsios, S.I.; Sarasidis, V.C.; Karabelas, A.J. A hybrid photocatalysis-ultrafiltration continuous process for humic acids degradation. Sep. Purif. Technol. 2013, 104, 333-341.

23. Berberidou, C.; Avlonitis, S.; Poulios, I. Dyestuff effluent treatment by integrated sequential photocatalytic oxidation and membrane filtration. Desalination 2009, 249, 1099-1106.

24. Martínez, F.; López-Muñoz, M.J.; Aguado, J.; Melero, J.A.; Arsuaga, J.; Sotto, A.; Molinaa, R.; Seguraa, Y.; Parientea, M.I.; Revillaa, A.; et al. Coupling membrane separation and photocatalytic oxidation processes for the degradation of pharmaceutical pollutants. Water Res. 2013, 47, 5647-5658. 
25. Mozia, S.; Darowna, D.; Szymański, K.; Grondzewska, S.; Borchert, K.; Wróbel, R.; Morawski, A.W. Performance of two photocatalytic membrane reactors for treatment of primary and secondary effluents. Catal. Today 2014, 236, 135-145.

26. Mozia, S.; Morawski, A.W.; Toyoda, M.; Inagaki, M. Effectiveness of photodecomposition of an azo dye on a novel anatase-phase $\mathrm{TiO} 2$ and two commercial photocatalysts in a photocatalytic membrane reactor (PMR). Sep. Purif. Technol. 2008, 63, 386-391.

27. Mendret, J.; Hatat-Fraile, M.; Rivallin, M.; Brosillon, S. Hydrophilic composite membranes for simultaneous separation and photocatalytic degradation of organic pollutants. Sep. Purif. Technol. 2013, 111, 9-19.

28. Grzechulska-Damszel, J.; Mozia, S.; Morawski, A.W. Integration of photocatalysis with membrane processes for purification of water contaminated with organic dyes. Catal. Today 2010, 156, 295-300.

29. Damodar, R.; You, S.-J.; Ou, S.-H. Coupling of membrane separation with photocatalytic slurry reactor for advanced dye wastewater treatment. Sep. Purif. Technol. 2010, 76, 64-71.

30. Ma, S.; Meng, J.; Li, J.; Zhang, Y.; Ni, L. Synthesis of catalytic polypropylene membranes enabling visible-light-driven photocatalytic degradation of dyes in water. J. Membr. Sci. 2014, 453, 221-229.

31. Paschoal, F.M.M.; Anderson, M.A.; Zanoni, M.V.B. The photoelectrocatalytic oxidative treatment of textile wastewater containing disperse dyes. Desalination 2009, 249, 1350-1355.

32. Rice, E.W.; Baird, R.B.; Eaton, A.D.; Clesceri, L.S. Standard Methods for the Examination of Water and Wastewater, 22nd ed.; American Public Health Association/American Water Works Association/Water Environment Federation: Washington, DC, USA, 2012.

33. Koh, J. Chapter 10: Dyeing with Disperse Dyes. In Textile Dyeing, 1st ed.; Hauser, P.J., Ed.; InTech: Rijeka, Croatia, 2011; pp. 195-220.

34. Boyjoo, Y.; Ang, M.; Pareek, V. Photocatalytic Treatment of Shower Water Using a Pilot Scale Reactor. Int. J. Photoenergy 2012, 2012, 1-7.

35. Bizani, E.; Fytianos, K.; Poulios, I.; Tsiridis, V. Photocatalytic decolorization and degradation of dye solutions and wastewaters in the presence of titanium dioxide. J. Hazard. Mater. 2006, 136, 85-94.

36. Visa, T.; Sánchez, M.; López-Grimau, V.; Navarro, R.; Reche, S.; Gutiérrez-Bouzán, M.C. Photocatalysis with titanium dioxide to remove colour of exhausted reactive dyebaths without $\mathrm{pH}$ modification. Desalin. Water Treat. 2012, 45, 91-99.

37. Muhammad, U.; Hamidi Abdul, A. Chapter 8: Photocatalytic Degradation of Organic Pollutants in Water. In Organic Pollutants - Monitoring, Risk and Treatment; InTech: Rijeka, Croatia, 2013; pp. 198-208.

38. Lu, C.S.; Mai, F.D.; Wu, C.W.; Wu, R.J.; Chen, C.C. Titanium dioxide-mediated photocatalytic degradation of Acridine Orange in aqueous suspensions under UV irradiation. Dyes Pigments 2008, 76, 706-713.

39. Liu, Y.; Hua, L.; Li, S. Photocatalytic degradation of Reactive Brilliant Blue KN-R by TiO2/UV process. Desalination 2010, 258, 48-53.

40. Toor, A.P.; Verma, A.; Jotshi, C.K.; Bajpai, P.K.; Singh, V. Photocatalytic degradation of Direct Yellow 12 dye using UV/TiO2 in a shallow pond slurry reactor. Dyes Pigments 2006, 68, 53-60.

41. Habib, A.; Ismail, I.M.I.; Mahmood, A.J.; Ullah, R. Photocatalytic decolorization of Brilliant Golden Yellow in TiO2 and ZnO suspensions. J. Saudi Chem. Soc. 2012, 16, 423-429. 
42. Liang, R.; Hu, A.; Wenjuan, L.; Zhou, Y. Enhanced degradation of persistent pharmaceuticals found in wastewater treatment effluents using TiO2 nanobelt photocatalysts. J. Nanoparticle Res. 2013, $15,1-13$.

43. Martínez, C.; Vilariño, S.; Fernández, M.I.; Faria, J.; Canle, M.; Santaballa, J.A. Mechanism of degradation of ketoprofen by heterogeneousphotocatalysis in aqueous solution. Appl. Catal. B Environ. 2013, 142-143, 633-646.

44. Li, D.; Zheng, H.; Wang, Q.; Wang, X.; Jiang, W.; Zhang, Z.; Yang, Y. A novel double-cylindrical-shell photoreactor immobilized with monolayer TiO2-coated silica gel beads for photocatalytic degradation of Rhodamine B and Methyl Orange in aqueous solution. Sep. Purif. Technol. 2014, 123, 130-138.

45. Buscio, V.; Marín, M.J.; Crespi, M.; Gutiérrez-Bouzán, C. Reuse of textile wastewater after homogenization-decantation treatment coupled to PVDF ultrafiltration membranes. Chem. Eng. J. 2015, 265, 122-128.

46. Mozia, S.; Morawski, A.W.; Toyoda, M.; Tsumura, T. Effect of process parameters on photodegradation of Acid Yellow 36 in a hybrid photocatalysis-membrane distillation system. Chem. Eng. J. 2009, 150, 152-159.

47. Mozia, S.; Morawski, A.W.; Toyoda, M.; Tsumura, T. Integration of photocatalysis and membrane distillation for removal of mono- and poly-azo dyes from water. Desalination 2010, 250, 666-672.

(C) 2015 by the authors; licensee MDPI, Basel, Switzerland. This article is an open access article distributed under the terms and conditions of the Creative Commons Attribution license (http://creativecommons.org/licenses/by/4.0/). 